\title{
PENGEMBANGAN PROGRAM MULTIMEDIA UNTUK MENINGKATKAN PENGUASAAN KOSAKATA BAHASA INGGRIS SISWA KELAS VII SMP DI BANJARBARU
}

\author{
Rahmad Hidayat ${ }^{1)}$, Endang Nurhayati ${ }^{2)}$ \\ Dinas Pendidikan Provinsi Kalimantan Selatan ${ }^{1)}$, Universitas Negeri Yogyakarta ${ }^{2)}$ \\ amd.smart@gmail.com ${ }^{1)}$, endang_fbs@yahoo.com ${ }^{2)}$
}

\begin{abstract}
Abstrak
Penelitian ini bertujuan menghasilkan program multimedia interaktif berbasis Flash untuk meningkatkan penguasaan kosakata siswa kelas VII SMP Kota Banjarbaru. Penelitian ini mengukur kualitas program ditinjau dari validasi ahli, penilaian pengguna dan hasil pretest-posttest. Pengembangan dilakukan melalui lima tahapan, yaitu: (1) analisis awal, (2) desain, (3) pengembangan program, (4) evaluasi, dan (5) pengemasan produk akhir. Subjek uji coba adalah siswa dan guru Bahasa Inggris kelas VII di SMP Negeri 11 Banjarbaru. Instrumen yang digunakan dalam pengumpulan data adalah lembar validasi, angket guru dan siswa, dan pretest-posttest. Hasil penelitian menunjukkan: (1) kualitas program dari segi materi dan media termasuk dalam kategori sangat baik dengan rerata skor 4,30 dan 4,44; (2) kualitas program dari penilaian guru dan siswa masuk dalam kategori baik dengan rerata skor 3,79 (guru) dan 4,18 (siswa); dan (3) terdapat peningkatan antara rerata skor hasil pretest $(61,33)$ dengan posttest $(85,2)$. Dengan demikian program multimedia yang dikembangkan cocok dan layak untuk digunakan dalam pembelajaran Bahasa Inggris di kelas.
\end{abstract}

Kata kunci: pengembangan program, multimedia, kosakata, Flash

\section{DEVELOPING MULTIMEDIA PROGRAM TO IMPROVE ENGLISH VOCABULARY MASTERY OF GRADE VII SMP STUDENTS IN BANJARBARU}

\begin{abstract}
This research is aimed to produce a Flash-based interactive multimedia program designed to improve the vocabulary mastery of grade VII Junior High School students in Banjarbaru. This research measures the quality of the program in terms of experts' validation, users' evaluation, and pretest-posttest result. The development was carried out within five phases, i.e.: (1) early analysis, (2) design, (3) program development, (4) evaluation, and (5) final product packing. The subjects were the grade VII students and English teacher in SMPN 11 Banjarbaru. The instruments used in data collection were the validation sheets, teacher's and students' questionnaire, and pretest-posttest. The result of the research shows that: (1) the quality of the program in terms of material and media aspects is included in the very good category with an average score of 4.30 and 4.44; (2) the quality of the program in terms of the teacher and students' evaluation is included in the good category with an average score of 3.79 (teacher) and 4.18 (students); and (3) there is an improvement between the average score of pretest (61.33) and posttest (85.2). Therefore, the program is suitable and appropriate to use in the classroom.
\end{abstract}

Keywords: program development, multimedia, vocabulary, Flash 


\section{PENDAHULUAN}

Kosakata adalah salah satu komponen utama dalam pengajaran Bahasa Inggris. Penguasaan kosakata esensial sifatnya dalam penguasaan semua keterampilan berbahasa, baik reseptif (listening dan reading) maupun produktif (speaking dan writing). Bidang ini belakangan semakin mendapat perhatian serius dari berbagai pihak. Sebagai contoh, The US. National Reading Panel dalam ikhtisarnya mencantumkan dengan jelas perlunya kosakata diajarkan secara langsung pada pengajaran reading (Hiebert \& Kamil, 2005, p.7).

Di Indonesia, Kurikulum Tingkat Satuan Pelajaran (KTSP) Bahasa Inggris SMP mengindikasikan perlunya pemahaman makna kata dalam standar kompetensi dan kompetensi dasarnya. Dalam keterampilan reading, misalnya, KTSP mensyaratkan siswa SMP agar dapat memahami makna dari beberapa jenis teks. Masalahnya, di Indonesia, Bahasa Inggris diajarkan sebagai bahasa asing, sehingga penggunaannya dalam komunikasi di masyarakat sangat terbatas (Sadtono, 2007, p.205). Akibatnya, siswa, khususnya siswa SMP hanya mendapat masukan leksikon Bahasa Inggris yang relatif sedikit. Tidak mengherankan jika siswa kerap mengalami kesulitan dalam memahami makna, baik tekstual maupun kontekstual dari kata-kata yang terdapat di dalam teks. Kesulitan ini bisa menjadi masalah yang serius, karena fokus utama materi Ujian Nasional SMP adalah pada pemahaman teks bacaan. Karenanya, penting bagi guru untuk meningkatkan penguasaan kosakata siswa sebagai pendukung peningkatan keterampilan reading siswa dan penunjang kesuksesan siswa dalam Ujian Nasional.

Bersama tata bahasa (grammar), kosakata memang menjadi komponen utama dalam pemerolehan dan pengajaran setiap bahasa. Menurut DeCarrico (2001, p.285) pembelajaran kosakata harus menjadi perhatian utama dalam penguasaan bahasa, baik itu bahasa pertama, kedua, maupun asing.

Di masa lalu, bidang kosakata ini seringkali diabaikan oleh para ahli. Kondisi ini terutama terjadi pada era linguistik struktural (1940-an hingga akhir 1970-an), yang lebih menekankan pentingnya tata bahasa dan fonologi. Kosakata baru mulai mendapat perhatian serius sejak era pendekatan komunikatif (communicative approach) seperti diperkenalkan oleh Hymes (1972) dan Halliday (1973). Sifat dasar pendekatan komunikatif, yang lebih mengutamakan kelancaran (fluency) ketimbang ketepatan (accuracy), pada gilirannya berfokus pada apa yang disebut sebagai "discourse-level functions" (fungsi-fungsi tingkat wacana) yang akhirnya lebih banyak berkenaan dengan pengetahuan leksikon yang diperlukan dalam situasi tertentu.

Studi-studi mengenai kosakata berkembang pesat sejak awal 1980-an, yang sebagian didukung oleh perkembangan dalam penelitian berbantuan komputer (computer-aided research), yang menyediakan basis data terkait kata-kata yang akan dipelajari (Thornbury 2002, p.vi). Dari sini, akhirnya diperoleh kesimpulan bahwa pada batas tertentu, ada kebutuhan untuk mengajarkan kosakata melalui pembelajaran eksplisit, di samping pengajaran implisit melalui kontekstualisasi yang telah biasa dilakukan. Pembelajaran kosakata secara eksplisit diperlukan untuk memfokuskan perhatian kepada katakata yang perlu dipahami oleh siswa sehingga dapat digunakan dengan optimal dalam keempat keterampilan berbahasa.

Guru dapat meningkatkan penguasaan kosakata dengan berbagai cara, salah satunya dengan memanfaatkan teknologi komputer. Perkembangan teknologi informatika dan komunikasi (TIK) saat ini telah berdampak positif terhadap pengajaran Bahasa Inggris, termasuk bidang kosakata. Dengan bantuan komputer, guru dapat menerapkan prinsip-prinsip pengajaran kosakata yang baik secara efektif, seperti perlunya ada proses pengulangan (repetition) dan pengingatan kembali (retrieval) (Nation, 2001, p.108).

Menurut Warren (2005, p.122), ICT dengan berbagai kelebihannya dapat memainkan peran yang istimewa di kelas. Dengan adanya lingkungan belajar yang menarik dan dinamis, siswa dapat belajar dengan motivasi tinggi.

Harrison (2004, p.88) menyatakan bahwa dukungan komputer sangat bermanfaat dalam pengembangan penguasaan kosakata. Harrison mencontohkan beberapa temuan, antara lain oleh Reinking \& Rickman (1990) dan Davidson, Elcock \& Noyes (1996). Harrison juga mengutip kesimpulan Ruddell (1994) yang berguna untuk memandu pengajaran kosakata, yang antara lain menyatakan: (1) Kosakata dipahami secara bertahap, tidak diserap sekaligus maupun ditolak sekaligus, (2) siswa belajar kosakata dengan lebih efektif jika pembelajarannya aktif dan sosial, dan (3) siswa dapat belajar kosakata dari konteks. 
National Reading Panel (2000, p.44) dalam 'Specific Conclusions about Vocabulary Instruction' menyatakan pada salah satu kesimpulannya (nomor 6) bahwa "teknologi komputer bisa digunakan secara efektif untuk membantu mengajarkan kosakata". Selain itu, DeCarrico (Celce-Murcia, 2001, p.288) menyatakan bahwa beragamnya ilustrasi yang dapat ditampilkan oleh program-program komputer, baik itu suara maupun gambar, dapat memberikan konteks yang beragam pula bagi siswa dalam berlatih kosakata.

Kemampuan komputer untuk menjalankan program multimedia adalah potensi yang sangat besar untuk meningkatkan kualitas proses dan hasil pembelajaran. Multimedia dirancang agar dapat secara simultan menampilkan teks, gambar, atau animasi dengan dukungan efek warna, suara, dan tingkat interaksi yang tinggi, yang bisa menghasilkan pengalaman belajar yang menarik dan berkesan bagi siswa.

Pembelajaran dengan multimedia saat ini cenderung semakin mendapat perhatian dan minat karena di kehidupan nyata, siswa juga telah terpapar oleh teknologi multimedia yang beragam bentuknya.

Fahy (2005, p.2) menyatakan bahwa kecenderungan ini diperkuat oleh temuan yang memperlihatkan bahwa penyampaian lewat multimedia dan internet lebih mudah diingat, memperluas jangkauan dan sumberdaya yang tersedia dalam situasi belajar, dan meningkatkan motiasi pengguna (Fischer, 1997; Bruce \& Levin, 1997; Mayer, 2001). Kontribusi teknologi multimedia terhadap pembelajaran antara lain adalah meningkatnya fleksibilitas, yang memberi akses dan kemudahan yang lebih besar bagi siswa, dan pilihan yang lebih beragam bagi pengguna sebagai individu dalam belajar (Fahy 2005, p.19).

Sokolik (Celce-Murcia, 2001， p.477) menyebutkan beberapa keuntungan dalam menggunakan komputer dalam pengajaran bahasa, antara lain: kemampuan untuk memfasilitasi drilling, adaptive testing, corpora and concordancing, dan multimedia production. Dengan menggunakan program multimedia, guru bisa menampilkan teks, gambar, dan suara, dan animasi secara bersamaan. Multimedia juga sangat interaktif, dan guru bisa membuat presentasi yang dihasilkan memiliki jalan cerita tertentu.

Dagdilelis dalam Mishra \& Sharma (2005, pp.116-117) mengemukakan tiga prinsip yang harus dimiliki oleh setiap perangkat lunak (software) untuk pendidikan, apapun bentuknya, termasuk multimedia. Prinsip-prinsip ini meliputi (1) logika alat, bahwa komputer dan TIK harus menjadi alat yang memudahkan pembelajaran, (2) multiple interface, bahwa tampilan antarmuka harus memungkinkan pengguna untuk tidak hanya memanipulasi objek, namun juga memberi perintah dan instruksi, dan (3) multiple representation, bahwa pengetahuan yang diajarkan tersampaikan melalui berbagai cara dan bentuk rancangan yang saling berkaitan. Tiga prinsip ini idealnya sangat mudah untuk dicapai dengan perangkat multimedia, karena sifat multimedia yang menggabungkan berbagai media dan metode penyampaian membuatnya terbuka untuk berbagai kemungkinan pengembangan.

Saat ini, dengan dukungan kemajuan TIK dan perkembangan perangkat keras dan lunak, telah banyak dikembangkan program untuk guru agar bisa merancang perangkat multimedia secara mandiri, yang diistilahkan sebagai authoring tools (Sánchez-Segura dalam Pagani, 2005: 935). Program ini memungkinkan guru untuk menyesuaikan materi yang ingin diajarkan dengan silabus, sekaligus menggabungkan berbagai media yang ada ke dalam satu paket pembelajaran. Program authoring tools bervariasi jenisnya, dari yang sederhana dengan prinsip 'drag and drop' seperti Microsoft Power Point, hingga yang sangat rumit dan berbasis bahasa pemrograman sekelas JavaScript seperti Java Eclipse. Di antara kedua kontinuum tersebut ada authoring tool dengan pemrograman berbasis objek (Object-oriented Programming) seperti Adobe Flash.

Adobe Flash, adalah program authoring tool yang banyak digunakan untuk menghasilkan konten multimedia dan animasi. Flash saat itu banyak digunakan di halaman jejaring, baik untuk menampilkan animasi, permainan, maupun sebagai pemutar musik dan video. Cikal bakal Flash dikembangkan sekitar 1994-96 oleh seorang programmer asal Amerika Serikat, Jonathan Gay, bersama timnya di studio Future Wave. Studio ini menghasilkan produk desain animasi bernama FutureSplash, yang kemudian dibeli oleh Macromedia dan dirilis dengan nama Macromedia Flash. Pada tahun 2005 Adobe mengakuisisi Macromedia, sehingga kemudian Flash berubah nama menjadi Adobe Flash (Warren, 2012).

Adobe Flash dapat digunakan untuk berbagai keperluan, seperti desain web, galeri foto, presentasi interaktif, dan lain-lain. Beberapa 
kalangan profesi yang banyak menggunakan Flash antara lain desainer grafis, animator, desainer web dan pengembang situs (Kerr \& Keats, 2009, p.34). Adobe Flash menggunakan sistem pemrograman berorientasi objek (OOP), yang memudahkan perancang multimedia dalam mengorganisir objek-objek yang sangat beragam (misalnya kumpulan gambar dan video/animasi), karena cara kerjanya mirip dengan bagaimana manusia mengelola benda-benda di sekitarnya (Dean \& Dean, 2008, pp.197-198).

Sebagai authoring tool, Flash memiliki beberapa keunggulan dalam penggunaannya, terutama jika dikaitkan dengan bidang pendidikan. Keunggulan yang pertama adalah animasi. Sebagai program yang utamanya didesain sebagai pengolah animasi, Flash sangat memudahkan perancang dalam mendesain berbagai animasi, baik dalam format 2 dimensi maupun 3 dimensi. Sistem frame dalam Flash memudahkan perancang menentukan berbagai factor dalam pembuatan animasi seperti durasi, jumlah frame per detik, (Green \& Stiller, 2009, p.14). Flash CS4 memiliki beberapa pilihan animasi atau disebut juga tweening, antara lain shape tweening, classic tweening, dan motion tweening. Untuk membantu menghasilkan animasi yang halus dan sesuai kebutuhan, Flash CS4 dilengkapi fasilitas seperti motion editor, motion path, easing, dan bone tools. Fitur-fitur ini cukup mudah untuk dipelajari dan bermanfaat untuk menghasilkan animasi yang hidup, sehingga guru bisa menampilkan animasi, seperti simulasi pengukuran dalam Matematika atau gerakan kerangka manusia dalam Biologi.

Keunggulan lainnya adalah integrasi dengan media lainnya. Flash dapat memuat gambar, suara dan video yang bisa digabungkan dalam satu paket presentasi. Setiap objek media ditampilkan dalam bentuk symbol yang hanya perlu dimasukkan sekali dalam library, untuk kemudian dapat dipanggil berkali-kali dalam kesempatan yang berbeda (Green \& Stiller, 2009, p.122). Ini membuat ukuran berkas Flash yang ukurannya bisa cukup kecil untuk diunggah ke halaman jejaring.

Selain itu ada pula components yang sudah tersedia secara default, seperti checkbox, radio button, slider, dan pemutar video. Semua komponen ini dapat dengan mudah dipanggil dan dimodifikasi sesuai keperluan. Penggunaan komponen dapat semakin meningkatkan tingkat interaksi pengguna dengan aplikasi yang dikembangkan.
Selain itu Flash CS4 menggunakan bahasa pemrograman baru, yaitu ActionScript 3.0, yang merupakan lompatan besar dalam bahasa pemrograman ketimbang pendahulunya, ActionScript 2. ActionScript 3.0 menggunakan system pengkodean yang jauh berbeda dan jauh lebih cepat dalam hal akses, dan lebih mudah dipahami logika pengoperasiannya. ActionScript 3.0 yang dikembangkan sejak 2006 saat ini menjadi bahasa pemrograman utama untuk programprogram berbasis Flash, di mana skrip yang digunakan mengacu pada standar bahasa yang digunakan oleh European Computer Manufacturers Association (ECMA Script), sehingga kompatibel untuk digunakan pada mayoritas komputer, sistem operasi, dan perambah jejaring saat ini, yang kebanyakan sudah mendukung JavaScript (Rosenzweig, 2011, p.2).

Dengan berbagai keunggulannya, guru dapat memaksimalkan potensi Flash untuk digunakan di ruang kelas. Guru dapat menggunakan audio, video dan gambar seperti layaknya kaset, pemutar video atau Flash-card. Bahkan dengan Flash media-media tersebut dapat dilengkapi dengan transkrip dan keterangan tambahan. Tambahan komponen bisa digunakan untuk membuat kuis sederhana, dan animasi dapat ditambahkan baik sebagai hiasan maupun sebagai penguat materi, seperti untuk menampilkan simulasi. Hal ini juga sangat bergantung pada kreativitas dan imajinasi guru sebagai pengembang dalam berkarya.

Meskipun hasil-hasil temuan terkait penggunaan multimedia menunjukkan hasil positif di beberapa negara dan wilayah di Indonesia, hanya sedikit, bahkan mungkin belum ada penelitian yang dilakukan bagi siswa di Kalimantan Selatan, khususnya Kota Banjarbaru. Sebagai calon Ibukota Provinsi Kalimantan Selatan, Banjarbaru telah berkembang pesat selama sepuluh tahun terakhir, termasuk di bidang pendidikan. Sebagian besar sekolah menengah telah dilengkapi dengan laboratorium bahasa, bahkan sebagian telah mendapat ruangan multimedia. Ketersediaan fasilitas ini idealnya bisa dimanfaatkan guru guna meningkatkan mutu pengajaran lewat penggunaan perangkat multimedia.

Sayangnya, kondisi di lapangan memperlihatkan bahwa hanya sedikit guru Bahasa Inggris SMP Kota Banjarbaru yang pernah memanfaatkan perangkat multimedia dalam pengajaran. Dari hasil pra-survei yang dilakukan peneliti, ditemukan bahwa kesulitan dalam mendapatkan program multimedia di pasaran dan keterbatasan guru dalam penguasaan 
fasilitas dan perangkat menjadi alasan sebagian guru tidak menggunakan multimedia.

Sementara itu, beberapa guru yang telah menggunakan multimedia mengalami masalah dalam menyesuaikan materi yang ada di program multimedia dengan kurikulum, serta menghadapi kendala teknis lainnya seperti seringnya listrik mengalami pemadaman dan kondisi ruangan yang tidak kondusif sebagai penghambat dalam penggunaannya. Dari berbagai masalah ini, dapat disimpulkan bahwa dari sisi guru, masih ada banyak masalah yang membuat penggunaan multimedia dalam pengajaran terhambat dan tidak efektif.

Dari hasil pra-survei ini juga terungkap bahwa sebagian besar guru belum pernah mendapat pelatihan atau bimbingan dalam menggunakan perangkat multimedia. Tidak familiarnya guru dengan perangkat multimedia bisa menjadi sumber lain keengganan guru dalam menggunakan multimedia, terutama karena adanya kekhawatiran munculnya kendala teknis pada saat pelaksanaan, yang berpotensi menghambat proses belajar mengajar. Hal ini sebenarnya patut disayangkan, karena semua responden menyatakan bahwa di sekolahnya terdapat fasilitas yang memadai untuk menjalankan perangkat multimedia.

Dari latar belakang dan masalah di atas, penelitian ini berfokus pada pengembangan program multimedia yang layak ditinjau dari aspek materi, media dan penggunaan, dan dapat meningkatkan penguasaan kosakata Bahasa Inggris siswa kelas VII SMP Kota Banjarbaru. Tujuannya adalah menghasilkan program multimedia yang layak pakai ditinjau dari aspek materi dan media, dapat digunakan dalam pengajaran Bahasa Inggris, khususnya untuk meningkatkan penguasaan kosakata siswa kelas VII SMP Kota Banjarbaru.

Program multimedia yang dikembangkan dikemas dalam dua format, yaitu CD pembelajaran interaktif dan installer berformat exe. Dalam program ini terdapat serangkaian kegiatan yang difokuskan pada peningkatan penguasaan kosakata Bahasa Inggris. Program ini antara lain memuat presentasi teks, soal-soal latihan, drill and practice, ilustrasi gambar, ilustrasi suara dan cara pengucapan, penggunaan dalam kalimat, serta permainan sederhana seperti mencocokkan gambar dan kata, mencari kata di dalam puzzle, dan menyusun kembali huruf yang acak menjadi kata.

Program yang dikembangkan meliputi (1) menu utama yang berisi pendahuluan (SK, KD,
Indikator, dan ringkasan materi), (2) materi pembelajaran yang terbagi menjadi beberapa kegiatan, dan (3) soal latihan. Program multimedia ini juga dilengkapi dengan ilustrasi grafis, suara, musik latar, dan tombol-tombol interaktif.

\section{METODE PENELITIAN}

\section{Jenis Penelitian}

Penelitian ini menggunakan jenis penelitian dan pengembangan yang tujuannya adalah menghasilkan produk yang efektif untuk digunakan di sekolah (Gay, 1987, p.8). Model pengembangan yang digunakan dalam penelitian ini diadaptasi dari desain pengembangan pengajaran berbasis multimedia Lee \& Owens (2004, p.3).

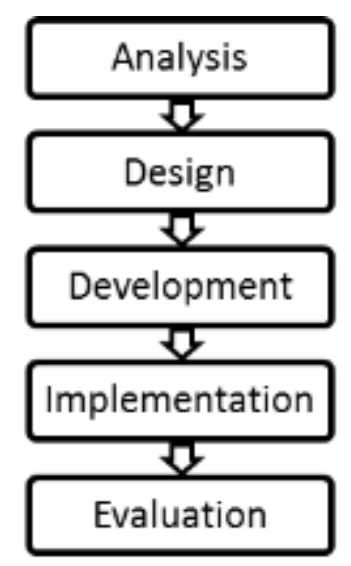

Gambar 1. Model Pengembangan Lee \& Owens (2004)

Model pengembangan dalam penelitian ini ini terbagi ke dalam lima tahapan yang terdiri atas analisis, desain, pengembangan, penerapan dan evaluasi.

\section{Prosedur Pengembangan}

Pada tahap analisis dilakukan: (a) observasi dan analisis kebutuhan guru dan siswa, (b) analisis silabus dalam rangka menentukan Standar Kompetensi, Kompetensi Dasar, dan indikator pembelajaran, (c) pemilihan topik dan penentuan materi yang akan dikembangkan, dan (d) pembuatan instrumen evaluasi.

Pada tahap desain dilakukan penyusunan course grid yang memuat $\mathrm{SK}, \mathrm{KD}$, indikator, daftar kosakata yang digunakan dan jenis aktivitas yang ada dalam setiap topik. Selanjutnya dibuat desain program multimedia dalam bentuk flowchart, storyboard dan layout. Selain itu dilakukan pula pengumpulan materi berupa gambar dan rekaman audio untuk mendukung pembelajaran. 
Pada tahap pengembangan, materi dan media dikompilasi ke dalam format program multimedia dengan bantuan perangkat lunak Adobe Flash CS4.

Pada tahap evaluasi program multimedia dievaluasi untuk mengukur kualitas program yang dihasilkan dengan melalui proses: (a) validasi ahli materi dan media, (b) penilaian siswa dan guru, (c) pretest dan posttest, dan (d) revisi produk. Hasil validasi ahli dan penilaian diukur dengan menggunakan analisis deskriptif, sementara hasil pretest dan posttest dibandingkan dengan uji-t menggunakan program SPSS.

Pada tahap terakhir dibuat produk akhir sesudah mengalami revisi berupa program multimedia yang dipaketkan ke dalam satu installer.

\section{Uji Coba Produk}

Produk yang dikembangkan diujicobakan melalui tiga tahapan. Pada tahap pertama, dilakukan pengujian dan validasi oleh ahli materi dan ahli media. Ahli materi menguji kualitas program dari segi materi, terutama yang berkaitan dengan pengajaran kosakata dalam Bahasa Inggris, sementara ahli media menguji kualitas program dari aspek rekayasa perangkat lunak dan komunikasi visual. Dari validasi ini diperoleh kritik dan masukan untuk dilakukan revisi program.

Pada tahap kedua, dilakukan praktik penggunaan program. Program diuji oleh yaitu guru dan siswa. Tahapan ini meliputi uji coba oleh guru secara perseorangan dan uji coba kepada siswa di kelas. Responden yang menguji kemudian memberikan penilaian dan pendapat mengenai program yang digunakan.

Sebelum dan sesudah uji coba, dilakukan evaluasi terhadap keefektifan program dalam meningkatkan penguasaan kosakata siswa. Evaluasi dilihat dari analisis perbandingan hasil pretest dan posttest yang diberikan kepada siswa. Skor yang didapat siswa dianalisis dengan menggunakan uji statistik menggunakan SPSS.

Yang menjadi subjek uji coba ini adalah siswa kelas VII SMPN 11 Banjarbaru dan guru pengajar Bahasa Inggris di kelas tersebut. Data yang diambil dalam tahap evaluasi ini berupa data kuantitatif dalam bentuk skor tanggapan ahli materi, ahli media, guru, dan siswa terhadap program yang dihasilkan, dan skor pretest dan posttest siswa. Selain itu ada pula data kualitatif berupa masukan dan saran dari ahli materi, ahli media, siswa dan guru tersebut.
Untuk pengambilan data pada tahap analisis awal, instrumen yang digunakan adalah observasi dan angket. Observasi dilakukan di SMPN 11 Banjarbaru, sedangkan angket diberikan kepada guru dan siswa untuk mengetahui kebutuhan guru dan siswa serta mengukur familiar tidaknya guru dan siswa terhadap program multimedia. Baik observasi maupun pemberian angket pra-survei dilakukan pada bulan Agustus 2012.

Untuk pengambilan data pada tahap evaluasi, instrumen yang digunakan adalah lembar penilaian, angket, dan soal pretest-posttest. Lembar penilaian diisi oleh ahli materi dan ahli media sebagai validasi terhadap program yang dikembangkan. Ahli materi dan media kemudian menentukan apakah program tersebut dapat digunakan tanpa perbaikan, ada perbaikan, atau dirombak total. Penilaian ahli materi mencakup aspek materi yang menyangkut kualitas dan kesesuaian isi materi, dan aspek pembelajaran yang menyangkut kualitas penyampaian materi. Penilaian ahli media meliputi aspek konten yang menyangkut kualitas media yang ditampilkan, dan aspek penggunaan yang menyangkut kualitas navigasi dan interaksi dalam program.

Angket juga diberikan kepada guru dan siswa untuk mengevaluasi kualitas program yang dikembangkan dan tingkat penerimaan guru dan siswa terhadap program yang digunakan. Dalam angket ini, guru memberikan penilaian baik terhadap aspek materi dan pembelajaran, seperti kesesuaian materi dengan silabus, dan penggunaan contoh, maupun aspek media, seperti kemudahan dalam menggunakan program maupun kualitas huruf, tombol, media audio dan gambar. Uji coba produk dilaksanakan pada bulan Desember 2012.

\section{Teknik Analisis Data}

Pada tahap pra-survei, siswa diberi angket yang bertujuan untuk mendukung data observasi. Data dianalisis dengan skala Guttman, dimana skor yang didapat adalah 0 dan 1 . Jawaban 'ya' bernilai 1 , sedangkan 'tidak' bernilai 0 .

Data kuantitatif dari angket berupa hasil penilaian ahli materi dan ahli media akan dianalisis dengan menggunakan skala Likert dengan penskoran 1-5, di mana kategori penilaiannya adalah: $5=$ sangat baik, $4=$ baik, $3=$ sedang, 2 $=$ rendah, dan $1=$ sangat rendah. Dari konversi di atas, maka didapat data kuantitatif dari hasil angket. Setelah itu, data kuantitatif dikonversi menjadi data kualitatif. 
Untuk menguji peningkatan penguasaan kosakata, dilakukan analisis statistik parametris dengan uji-t (Sugiyono, 2010, p.121). Dalam uji coba ini dilakukan perbandingan antara hasil sebelum pembelajaran dengan program multimedia dan sesudah pembelajaran. Sebagai sampel diambil secara acak 30 siswa dari kelas VIIB dan diberikan pretest, perlakuan, dan posttest. Hipotesis uji coba ini adalah:

Ho: Tidak terdapat perbedaan tingkat penguasaan kosakata siswa antara sebelum dan setelah mendapat pembelajaran dengan multimedia.

Ha: Terdapat perbedaan tingkat penguasaan kosakata siswa antara sebelum dan setelah mendapat pembelajaran dengan multimedia.

Nilai pretest dan posttest dibandingkan untuk kemudian dihitung dengan menggunakan uji-t dengan menggunakan program SPSS. Jika terdapat perbedaan nilai t-hitung antara hasil pretest dengan hasil posttest, maka Ho ditolak dan Ha diterima.

\section{HASIL PENELITIAN DAN PEMBAHASAN}

Setelah program selesai dikembangkan, dilakukan evaluasi oleh ahli materi dan ahli media. Dari hasil evaluasi ahli materi terlihat kalau program yang dikembangkan, ditinjau dari aspek materi masuk dalam kategori sangat baik, dengan rerata skor 4,33 dan dari aspek pembelajaran masuk dalam kategori sangat baik dengan rerata skor 4,27 .

Dari hasil evaluasi ahli media, terlihat bahwa rerata skor penilaian ahli media pada aspek konten adalah 4,38 dari 13 aspek yang dinilai, sehingga dari aspek konten, program ini dikategorikan sangat baik. Dari aspek penggunaan, rerata skor penilaian yang didapat adalah 4,50 dari 10 aspek yang dinilai, sehingga program ini juga masuk dalam kategori sangat baik. Dengan demikian program multimedia ini layak untuk diujicobakan.

Sebelum diujicobakan, program ini disempurnakan terlebih dahulu dengan mengacu pada saran-saran revisi yang diberikan oleh ahli materi dan ahli media.

Uji coba dilaksanakan dengan melibatkan siswa kelas VII SMPN 11 Banjarbaru. Dalam uji coba ini dipilih secara acak siswa kelas VIIC untuk diberikan materi dengan menggunakan program multimedia. Uji coba dilaksanakan dalam satu kali pertemuan dengan alokasi waktu $2 \times 40$ menit.

Proses pembelajaran dengan menggunakan program yang dikembangkan dilaksanakan pada tanggal 27 Desember 2012. Selama proses pembelajaran peneliti berperan sebagai guru sekaligus operator program. Mengingat keterbatasan jumlah komputer, pembelajaran dilakukan dengan memakai fasilitas proyektor LCD dan pengeras suara. Siswa diberikan presentasi, dan bersama-sama menjawab pertanyaan yang ditampilkan di layar. Pada kegiatan interaktif, beberapa siswa secara bergantian ditunjuk untuk maju ke depan dan mengerjakan aktivitas tersebut.

Penilaian siswa terhadap program menunjukan bahwa program ini tergolong dalam kategori baik dengan rerata skor keseluruhan 4,18. Sementara itu, penilaian guru Bahasa Inggris terhadap program menunjukkan bahwa program ini, ditinjau dari aspek pembelajaran dan materi dikategorikan baik dengan rerata skor 3,7, dan ditinjau dari aspek media masuk dalam kategori baik dengan rerata skor 3,88. Secara keseluruhan, penilaian guru pengampu menunjukkan bahwa program ini masuk dalam kategori baik dengan rerata skor 3,79.

Pada uji coba ini, siswa kelas VIIC juga memberikan masukan maupun saran terhadap program yang dikembangkan.

Untuk melihat peningkatan penguasaan kosakata siswa, digunakan analisis dengan uji-t. Dari tes yang diberikan kepada para siswa kelas VIIB sebagai sampel, diperoleh hasil rata-rata skor pretest sebesar 61,33 dan hasil rata-rata skor posttest sebesar 85,2. Setelah dilakukan uji normalitas dengan program SPSS, didapat hasil bahwa baik skor pretest maupun posttest terlihat berdistribusi normal. Hasil uji normalitas pretest dan posttest masing-masing dapat dilihat pada tabel berikut.

Tabel 1. Hasil Uji Normalitas Pretest dan Posttest

One-Sample Kolmogorov-Smirnov Test

\begin{tabular}{ccc}
\hline & & Pretest \\
\hline & $N$ & 30 \\
\hline Normal $^{a}$ & Mean & 61.3333 \\
Parameters $^{a}$ & Std. Deviation & 8.55543 \\
Most & Absolute & .100 \\
Extreme & Positive & .100 \\
Differences & Negative & -.094 \\
Kolmogorov-Smirnov Z & .549
\end{tabular}


Asymp. Sig. (2-tailed)

.924

a. Test distribution is Normal.

\begin{tabular}{ccc}
\hline & & Posttest \\
\hline & $N$ & 30 \\
\hline Normal $^{a}$ & Mean & 85.2000 \\
Parameters $^{a}$ & Std. Deviation & 9.46281 \\
Most & Absolute & .216 \\
Extreme & Positive & .117 \\
Differences & Negative & -.216 \\
Kolmogorov-Smirnov Z & 1.185 \\
Asymp. Sig. (2-tailed) & .121 \\
\hline \multicolumn{2}{c}{ a. Test distribution is } \\
\multicolumn{2}{c}{ Normal. }
\end{tabular}

Selanjutnya, data yang ada dianalisis dengan menggunakan uji-t berpasangan. Dari hasil analisis dengan program SPSS, didapat hasil seperti ditampilkan pada tabel 2 di bawah ini.

Tabel 2. Hasil Uji-t pada Pretest-Posttest

\begin{tabular}{|c|c|c|c|c|c|}
\hline \multicolumn{6}{|c|}{ Paired Samples Statistics } \\
\hline & & Mean & $N$ & StDev & $\begin{array}{c}\text { Std. Error } \\
\text { Mean }\end{array}$ \\
\hline \multirow{3}{*}{$P 1$} & Pre & 61.33 & 30 & 8.555 & 1.562 \\
\hline & Post & 85.20 & 30 & 9.463 & 1.728 \\
\hline & $N$ & \multicolumn{2}{|c|}{ Correlation } & \multicolumn{2}{|c|}{ Sig. } \\
\hline$P 1$ & 30 & \multicolumn{2}{|c|}{.702} & \multicolumn{2}{|c|}{.000} \\
\hline
\end{tabular}

\begin{tabular}{ll}
\hline Paired Differences \\
\hline Mean Std. Deviation $\quad$ Std. Error Mean \\
\hline
\end{tabular}

$-23.867$

7.006

1.279

95\% Confidence Interval of the

Difference

\begin{tabular}{cll} 
Lower & Upper & \multicolumn{1}{c}{$t$} \\
-26.483 & -21.251 & -18.659 \\
Df & Sig. (2-tailed) & \\
& 29 & \multicolumn{2}{c}{.000}
\end{tabular}

Dari tabel output uji-t tersebut dapat disimpulkan antara lain: (a) nilai korelasi antara kedua variabel di atas sebesar 0,702 artinya hubungan kuat dan positif, (b) tingkat signifikansi hubungan pada 0,000 artinya signfikan pada level 0,01 , (c) nilai -t hitung yang didapat sebesar -18,659 lebih kecil dari nilai -t tabel untuk $\mathrm{df}=29$ sebesar $-2,045$, maka perbedaannya signifikan, dan (d) perbedaan nilai rata-rata siswa sebesar -23.867 bernilai negatif, yang mana berarti terjadi kecenderungan peningkatan antara sebelum dan sesudah pembelajaran dengan multimedia. Dengan demikian, maka Ho ditolak dan Ha diterima.

Dari hasil evaluasi ahli materi, ahli media, guru, dan uji coba kepada siswa diperoleh masukan dan saran yang berguna dalam melakukan revisi program. Revisi yang dilakukan terhadap program ini antara lain meliputi perbaikan course grid, perombakan sistem navigasi program agar lebih mudah untuk digunakan, penambahan variasi aktivitas, dan perbaikan volume audio.

\section{SIMPULAN}

\section{Simpulan}

Pengembangan program multimedia untuk meningkatkan kosakata Bahasa Inggris siswa kelas VII SMP di Banjarbaru ini dilakukan dengan melewati beberapa tahapan, yaitu: (1) analisis awal, (2) desain, (3) pengembangan produk, (4) evaluasi program, dan (5) pengemasan produk akhir. Produk yang dihasilkan dikemas dalam bentuk installer dan $\mathrm{CD}$.

Berdasarkan hasil analisis data penelitian dan pengembangan di lapangan dapat disimpulkan sebagai berikut: (1) kualitas program multimedia yang dikembangkan ditinjau dari aspek materi dan media masuk dalam kategori sangat baik dengan rerata skor 4,30 untuk aspek materi dan 4,44 untuk aspek media, (2) kualitas program ini ditinjau dari penilaian guru dan siswa pada uji coba termasuk dalam kategori baik, dengan rerata skor oleh guru sebesar 3,79, dan oleh siswa sebesar 4,18, (3) terdapat peningkatan antara hasil pretest dengan rerata skor sebesar 61,33 dengan hasil posttest dengan rerata skor sebesar 85,2.

Dari hasil validasi ahli materi dan ahli media, penilaian guru dan siswa, serta peningkatan penguasaan kosakata tersebut dapat disimpulkan bahwa program multimedia yang dikembangkan cocok dan layak untuk digunakan dalam pembelajaran Bahasa Inggris di kelas.

\section{DAFTAR PUSTAKA}

Badan Standar Nasional Pendidikan. (2008). Panduan penyusunan KTSP dan Silabus.

Dagdilelis, V. (2005). Principles of educational software design. Dalam S. Mishra \& R. C. Sharma, Interactive multimedia in education and training (Eds.) (pp.1-24). Hershey: Idea Group Publishing. 
Dean, J., \& Dean, R.H. (2008). Introduction to programming with Java: a problem solving approach. New York: McGrawHill.

DeCarrico, J. S. (2001). Vocabulary learning and teaching. Dalam M. Celce-Murcia (Ed.), Teaching English as a Second or Foreign Language ( ${ }^{\text {rd }}$ ed.) (pp.285299). Boston: Heinle \& Heinle.

Depdiknas. (2005). Peraturan Pemerintah Nomor 19 Tahun 2005 Tentang Standar Nasional Pendidikan.

Sadtono, Eugenius. (2007). A concise history of teaching English as a foreign language in Indonesia. Dalam Yeon Hee Choi \& B. Spolsky (Eds.), English Education in Asia; History and Policies (pp.205231). Seoul: Asia TEFL.

Fahy, P. J. (2005). Planning for multimedia learning. Dalam S. Mishra \& R. C. Sharma, Interactive multimedia in education and training (Eds.) (pp.1-24). Hershey: Idea Group Publishing.

Gay, L.R. (1987). Educational research: competencies for analysis and application $\left(3^{\text {rd }}\right.$ ed.). Columbus: Merrill Publishing Company.

Green, T. \& Stiller, D. (2009). Foundation Flash CS4 for Designers. New York: Friendsof-Apress.

Halliday, M. A. K, Teubert, W., Yallop, C., et al. (2004). Lexicology and corpus linguistics. London: Continuum.

Harrison, Colin, (2004), Understanding Reading Development, London, SAGE Publications Ltd.

Kamil, M. \& Hiebert, E.H. (2005). Teaching and Learning Vocabulary: Perspectives and Persistent Issues. Dalam E.H. Hiebert, \& M. Kamil, Teaching and learning vocabulary; bringing research to practice (Eds) (pp.1-23). London: Lawrence Erlbaum Associates, Inc.

Kerr, C. \& Keats, J. (2009). The essential guide to Flash CS4. New York: FriendsofApress.

Lee, W.W. \& Owens, D.L. (2004). Multimediabased instructional design ( $2^{\text {nd }} e d$.). San Francisco: Pfeiffer.
Nagy, W. (2005). Why vocabulary instruction needs to be long-term and comprehensive. Dalam E.H. Hiebert, \& M. Kamil, Teaching and learning vocabulary; bringing research to practice (Eds) (pp.27-44). London: Lawrence Erlbaum Associates, Inc.

Nation, I. S. P. (2001). Learning vocabulary in another language. Cambridge: Cambridge University Press.

Akbari, Omid. (2008). Teaching vocabulary items through contextualization and picture to elementary Iranian EFL students. The Asian EFL Journal, 3, 5377. Diambil pada tanggal 11 Juli 2011, dari http://asian-efljournal.com/quarterlyjournal/2008/09/26/teachingvocabulary-items-throughcontextualization-and-picture-toelementary-iranian-efl-students/

Pagani, M. (Ed.) (2005). Encyclopedia of multimedia technology and networking. Hershey: Idea Group Inc.

Rosenzweig, G. (2011). ActionScript 3.0 game programming university $\left(2^{\text {nd }} e d.\right)$. Indianapolis: Que Publishing.

Sato, T., \& Suzuki, A. (2010). Do multimediaoriented visual glosses really facilitate EFL vocabulary learning?: A comparison of planar images with threedimensional images. The Asian EFL Journal Special Issue, 12, 160-172. Diambil pada tanggal 11 Juli 2011, dari http://asian-efl-journal.com/quarterlyjournal/2010/12/24/do-multimediaoriented-visual-glosses-really-facilitateefl-vocabulary-learning-a-comparisonof-planar-images-with-threedimensional-images/

Sokolik, M. (2001). Computers in language teaching. Dalam M. Celce-Murcia (Ed.), Teaching English as a Second or Foreign Language ( $3^{\text {rd }}$ ed.) (pp.477488). Boston: Heinle \& Heinle.

Sudaryanto. (2010). Pengembangan multimedia pembelajaran Bahasa Inggris dengan program Macromedia Flash MX 2004 untuk memotivasi dan meningkatkan hasil belajar siswa SMP. Tesis magister, tidak diterbitkan, Universitas Negeri Yogyakarta, Yogyakarta. 
Sugiyono. (2010). Metode penelitian pendidikan: pendekatan kuantitatif, kualitatif, dan $R \& D$. Bandung: Penerbit Alfabeta.

Thornbury, S. (2002). How to teach vocabulary. Edinburgh: Pearson Education Limited.

Warren, C. (2005). Information and Communications Technology. Dalam A. Goodwyn \& J. Branson, Teaching English, a handbook for primary and secondary school teachers (Eds.) (pp.104-122). London: Routledge.

Warren, C. (19 November 2012). The life, death and rebirth of Adobe Flash. Diambil pada tanggal 4 April 2013 dari http://mashable.com/

2012/11/19/history-of-Flash/ 